\section{Impact of Root Growth on the Physical Properties of Peat Substrate under a Constant Water Regimen}

\author{
Patrice Cannavo ${ }^{2}$, Houda Hafdhi ${ }^{1}$, and Jean-Charles Michel \\ Agrocampus Ouest-Centre d'Angers, UP EPHor, 2 rue André Le Nôtre, 49045 \\ Angers, France
}

Additional index words. peat substrate, 'New Guinea' impatiens, root, soil water retention, soil hydraulic conductivity, porosity

\begin{abstract}
The impact of root growth on the hydraulic properties of peat substrate was investigated under optimal water retention, i.e., at a constant water potential of $-1 \mathrm{kPa}$. 'New Guinea' impatiens was grown in 1.1-L cylindrical containers for $196 \mathrm{~d}$ in a greenhouse under controlled climate and fertilization conditions. Water retention and hydraulic conductivity curves, root biomass and volume, and shoot weight were measured. Results indicated a maximal root volumetric content of $0.065 \mathrm{~m}^{3} \cdot \mathrm{m}^{-3}$ that was as high as the peat content in containers $\left(0.068 \mathrm{~m}^{3} \cdot \mathrm{m}^{-3}\right)$. From Day 0 to Day 196, the total porosity of the growing media decreased from $0.931 \mathrm{~m}^{3} \cdot \mathrm{m}^{-3}$ to $0.874 \mathrm{~m}^{3} \cdot \mathrm{m}^{-3}$. Moreover, considering the water-holding capacity at a water potential of $-1 \mathrm{kPa}$, it increased from 0.58 to $0.75 \mathrm{~m}^{3} \cdot \mathrm{m}^{-3}$ (i.e., by $29.3 \%$ ) without changes in water availability but with a large decrease in air-filled porosity from 0.35 to $0.14 \mathrm{~m}^{3} \cdot \mathrm{m}^{-3}$. The unsaturated hydraulic conductivity $K(\theta)$ decreased as a result of root growth. Root growth also modified pore size distribution and pore structure. Hydraulic conductivity curves indicated a better pore connectivity reflected by a decrease in tortuosity.
\end{abstract}

Plants growing in pots or containers are generally limited by the volume of substrate in which water, gas, and solute availability can fluctuate over a short period of time (a few hours) (Polak and Wallach, 2001). Mathers et al. (2007) present an extensive list of abiotic factors that influence root growth in containers in their review. Among them, the physical properties of growing substrate are of great importance. The air-filled porosity and the water retention capacity and availability have a considerable impact on plant growth.

The hydraulic properties of growing media generally provide precise information about their ability to provide good growth conditions. Peat, especially slightly decomposed sphagnum peat, is a growing medium widely used to grow ornamental plants worldwide (Schmilewski, 2009). This type of raw material is often considered as an ideal organic material for irrigation management as a result of its airfilled porosity and its water availability, often higher than $0.2 \mathrm{~m}^{3} \cdot \mathrm{m}^{-3}$ and $0.25 \mathrm{~m}^{3} \cdot \mathrm{m}^{-3}$,

Received for publication 3 May 2011. Accepted for publication 22 Aug. 2011.

This study was carried out within the EPHor research unit at Agrocampus Ouest, Centre of Angers. We thank all of the people who contributed to this work. First, special thanks are in order to FALIENOR for providing the peat. Second, we express our gratitude to Yvette Barraud-Roussel, Sylviane DelepineBourgeois, and Claudie Mazzega who were responsible for the laboratory measurements.

${ }^{1}$ Current address: INRA, US Agro-Impact, Site de Laon, Pôle du Griffon, 180 rue Pierre-Gilles de Gennes, 02000 Barenton-Bugny, France.

${ }^{2}$ To whom reprint requests should be addressed; e-mail patrice.cannavo@agrocampus-ouest.fr. respectively (Riviere et al., 1990). Recent studies on peat aeration have reported that peat particle size does not affect the air-filled porosity but instead influences gas relative diffusivity (Caron et al., 2010). In contrast to other organic growing media, peat decomposition is very low, conferring considerable biological stability over time. However, three main factors can affect the physical properties of peat: the change in particle size and particle distribution (Qi et al., 2011), the possible water repellency of the media (Michel et al., 2001; Naasz et al., 2008), its possible biological degradation, and root growth (Allaire-Leung et al., 1999).

The influence of root growth on the physical properties of growing media is poorly documented with unconvincing and contradictory results. This may be explained by highly variable water irrigation regimens in the different trials, which can modify particle distribution and porosity. As reported by Allaire-Leung et al. (1999), root growth leads to a decrease in porosity as roots grow in the gaseous phase of the porosity, i.e., the macroporosity. Furthermore, root elongation promotes pore modifications and often decreases tortuosity (Nkongolo and Caron, 2006a, 2006b). These results in pore space organization may have a direct impact on the hydraulic properties of peat. Several authors have mentioned an increase in water-holding capacity (Favaro and Marano, 2003; Fonteno, 1996). Although Allaire-Leung et al. (1999) did not observe significant changes in saturated hydraulic conductivity, other authors observed a decrease in the saturated hydraulic conductivity (Gruda and Schnitzler, 2003) between the beginning and the end of plant growth in various growing media. However, the direct impact of root growth on the hydraulic properties of peat largely depends on the biotic and abiotic factors that can influence these properties. In particular, the control of water irrigation is of great importance. Depending on the water regimen, drying/wetting cycles and their different intensities are known to exhibit more or less reversible hysteresis phenomena in peat hydraulic properties (Naasz et al., 2005) with possible shrinkage/swelling processes and changes in wettability (Michel et al., 2004; Qi et al., 2011). Moreover, roots may be affected by a dry water regimen with possible preferential root growth within the wetting zone in containers.

Thus, the objective of the present study was to analyze peat hydraulic properties under the influence of time and of root growth of 'New Guinea' impatiens under optimal water retention conditions, i.e., at a constant water potential of $-1 \mathrm{kPa}$, as defined by Fonteno (1989), the EN 13041 standard (EN 13041, 2000), and Riviere et al. (1990), and Verdonck et al. (1978).

\section{Materials and Methods}

Site description and experimental design

The experiment was carried out in a $93.1-\mathrm{m}^{2}$ $(9.7 \mathrm{~m} \times 9.6 \mathrm{~m})$ greenhouse at Agrocampus Ouest-Center d'Angers, France (lat. $47^{\circ} 30^{\prime} \mathrm{N}$; long. $\left.00^{\circ} 35^{\prime} \mathrm{W}\right)$. The climate was automatically controlled with air temperature maintained at a minimum of $20^{\circ} \mathrm{C}$ and ventilation if the air temperature exceeded $22^{\circ} \mathrm{C}\left( \pm 1^{\circ} \mathrm{C}\right)$. The growing medium used was a weakly decomposed sphagnum peat from Ireland with a particle size range of 5 to $20 \mathrm{~mm}$. The chemical characteristics were as follows: $\mathrm{pH}_{\mathrm{H} 2 \mathrm{O}} 6$ [5:1 water:peat ratio; EN 13037 (2000)]; electric conductivity: $450 \mathrm{dS} \cdot \mathrm{m}^{-1}$ [5:1 water:peat ratio, EN 13038 (2000)]; organic matter content: $930 \mathrm{~g} \cdot \mathrm{kg}^{-1}$; and carbon:nitrogen ratio of organic matter: 54.2 (EN 13039, 2000). The 'New Guinea' impatiens (cv. Sonic Scarlet variety) was used to study the impact of its root growth on peat hydraulic properties. This plant has the advantage of having a short development cycle ( $\approx 6$ months). Moreover, it is characterized by high transpiration and high sensitivity to water stress, thereby justifying the use of peat.

Cylindrical polyvinyl chloride containers were used for the experiment (Fig. 1A). They consisted of two sections. The first section (height: $0.10 \mathrm{~m}$; internal diameter: $0.12 \mathrm{~m}$ ) was filled with fresh peat to obtain a dry bulk density of $0.107 \mathrm{~g} \cdot \mathrm{cm}^{-3}(\approx 336 \mathrm{~g}$ of fresh peat per cylinder). The second section (height: $0.02 \mathrm{~m}$; internal diameter: $0.12 \mathrm{~m}$ ) was attached to the first one to prevent peat losses during filling and, subsequently, in the case of peat swelling when wetted. The cylinder was then placed on a 3.0 $\times 2.4-\mathrm{m}$ table in the greenhouse. This table was covered beforehand with an Aquanap ${ }^{\circledR}$ irrigation sheet (Puteaux SA, Les Clayes sous Bois, France). Aquanap ${ }^{\circledR}$ was made of finely shredded recycled cloth pressed into a $5 \mathrm{~mm}$ thick layer and is able to retain 10 times its weight in water. It is the means by which the nutrient solution is supplied to the plants. 
A

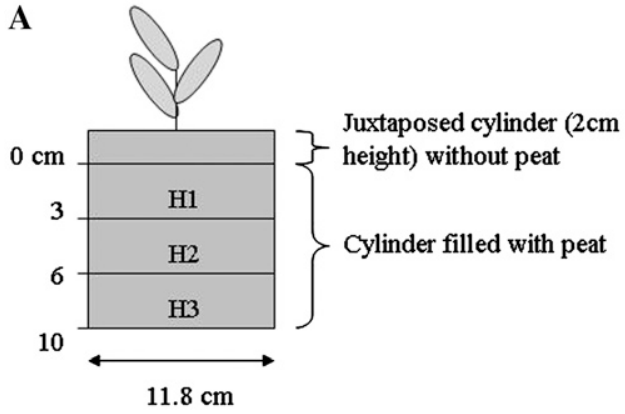

B

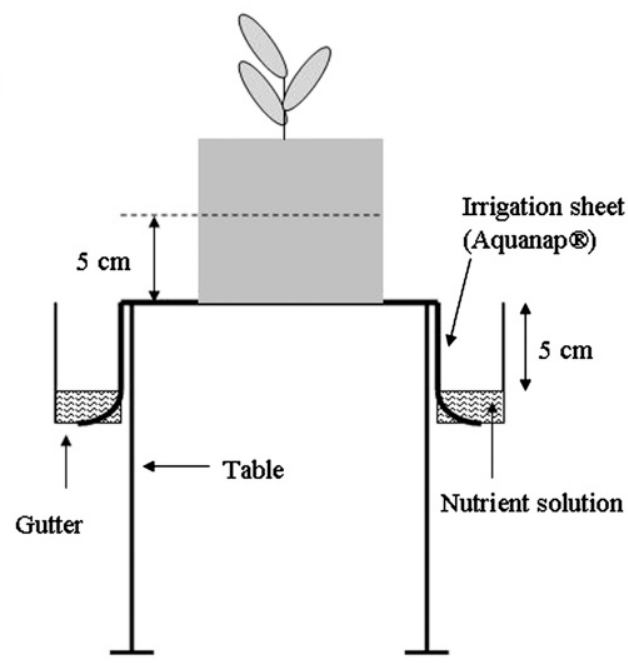

Fig. 1. Experimental design. (A) Sample layer organization; (B) irrigation layout.

Detailed hydraulic properties are presented in Morel and Berthier (2005). A gutter was fixed to each end of the table and contained irrigation water that was maintained at a constant level. The extremities of the irrigation sheet were bathed in this water (Fig. 1B). The water level was adjusted to obtain a permanent water suction of $-0.1 \mathrm{~m}(-1 \mathrm{kPa})$ at the middle of the peat cylinder, corresponding to the waterholding capacity of the peat. Two tensiometers were installed in containers to follow and validate the constant water regimen. Irrigation water was fertilized with $2 \mathrm{~N}-3 \mathrm{P}-6 \mathrm{~K}+$ $0.6 \mathrm{MgO}\left(9.6 \mathrm{mmol} \mathrm{N}-\mathrm{NO}_{3} / \mathrm{L}, 1.8 \mathrm{mmol} \mathrm{PO}_{4} / \mathrm{L}\right.$, $6.1 \mathrm{mmol} \mathrm{K} / \mathrm{L}$. and $0.9 \mathrm{mmol} \mathrm{Mg} / \mathrm{L}$ ).

The experiment began in Mar. 2010 and ended in Sept. 2010. The sampling protocol consisted of six replicates without plants (called "no plant" or NP) and 12 replicates with plants (called P). In NP replicates, three were used for volumetric water content measurement (Fig. 1A). The other three were used for water retention curve measurements. In $P$ replicates, three were used for gravimetric water content measurement, six for shoot weight and root biomass quantification, and the last three replicates for water retention curve measurements. Additionally, at Time 0 and at the end of the experiment, two replicates of NP (for Time 0 ) and two replicates of $\mathrm{P}$ (end of the experiment) were used for peat hydraulic conductivity measurements. Thus, 15 cylinders were sampled every $\approx 30 \mathrm{~d}$, representing a total of 100 cylinders randomly placed on the table.

Three $\mathrm{d}$ before the beginning of the experiment, the 100 cylinders were filled with peat and placed on the irrigation sheet saturated with water. At Day 0, cuttings of impatiens were carefully potted to avoid modifying the initial peat bulk density. Moreover, six cuttings were analyzed for initial root biomass and shoot weight. The experiment lasted for 196 d. During the experiment, flowers were systematically removed to favor shoot weight development.

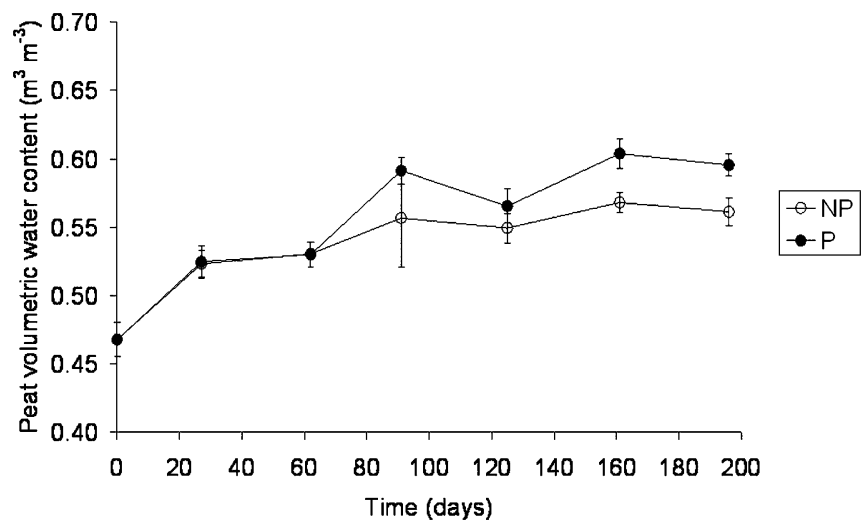

Fig. 2. Mean peat volumetric water content evolution during the 196-d experiment. Data obtained from peat with 'New Guinea' impatiens (P) and without 'New Guinea' impatiens (NP). Bars represent SES $(\mathrm{n}=3)$.

\section{Plant growth and peat physical properties}

Immediately after removal from the table, the plant shoots were cut at the peat-atmosphere interface, weighed, oven-dried at $65^{\circ} \mathrm{C}$ for $72 \mathrm{~h}$, and weighed again. The roots were first washed with water to separate them from the peat and then weighed. The fresh root volume was then measured. To do this, roots were put in a tea ball and then plunged into a basin filled with water and placed on a precision balance. The same was done without fresh roots. After this, roots were oven-dried at $65{ }^{\circ} \mathrm{C}$ for $72 \mathrm{~h}$ to estimate their dry biomass.

Peat gravimetric water content was calculated after oven-drying at $105^{\circ} \mathrm{C}$ for $48 \mathrm{~h}$. Volumetric water content was obtained from the gravimetric water content and the peat bulk density. Every $30 \mathrm{~d}$, the peat bulk density was calculated as follows:

$$
B_{d}=\frac{D W}{V_{c}-V_{r}}
$$

where $B_{d}$ is the bulk density $\left(\mathrm{g} \cdot \mathrm{m}^{-3}\right), D W$ is the peat dry weight $(\mathrm{g}), V_{c}$ is the cylinder volume $\left(1.09310^{-3} \mathrm{~m}^{3}\right)$, and $V_{r}$ is the root volume $\left(\mathrm{m}^{3}\right)$.
Total porosity. The total porosity Pt of peat was calculated using the following formula:

$$
P t=\frac{V_{c}-\left(V_{r}+V_{p}\right)}{V_{c}}
$$

where $P t$ is expressed in $\mathrm{m}^{3} \cdot \mathrm{m}^{-3}$ and $\mathrm{V}_{\mathrm{p}}$ is the volume of peat $\left(\mathrm{m}^{3}\right)$, calculated by dividing the peat dry mass by its particle density, 1.55 $\mathrm{g} \cdot \mathrm{cm}^{-3}$, estimated by the method of Lemaire et al. (2003).

Water retention curves. Water retention properties were determined using standardized hydrostat methods (EN 13041, 2000). After cutting the aerial part, the cylinder was saturated in water for $24 \mathrm{~h}$ and then placed on the tension table to drain the substrate at -1 , $-3.16,-5$, and $-10 \mathrm{kPa}$. Cylinders were covered with plastic to prevent evaporation.

Unsaturated hydraulic conductivity. The instantaneous profile method was used to establish the unsaturated hydraulic conductivity curve. The experimental design is detailed in Naasz et al. (2005). Two time domain reflectometry mini-probes and two mini-tensiometers were introduced into the substrate cylinder at depths of 0.03 and $0.08 \mathrm{~m}$. Direct and 

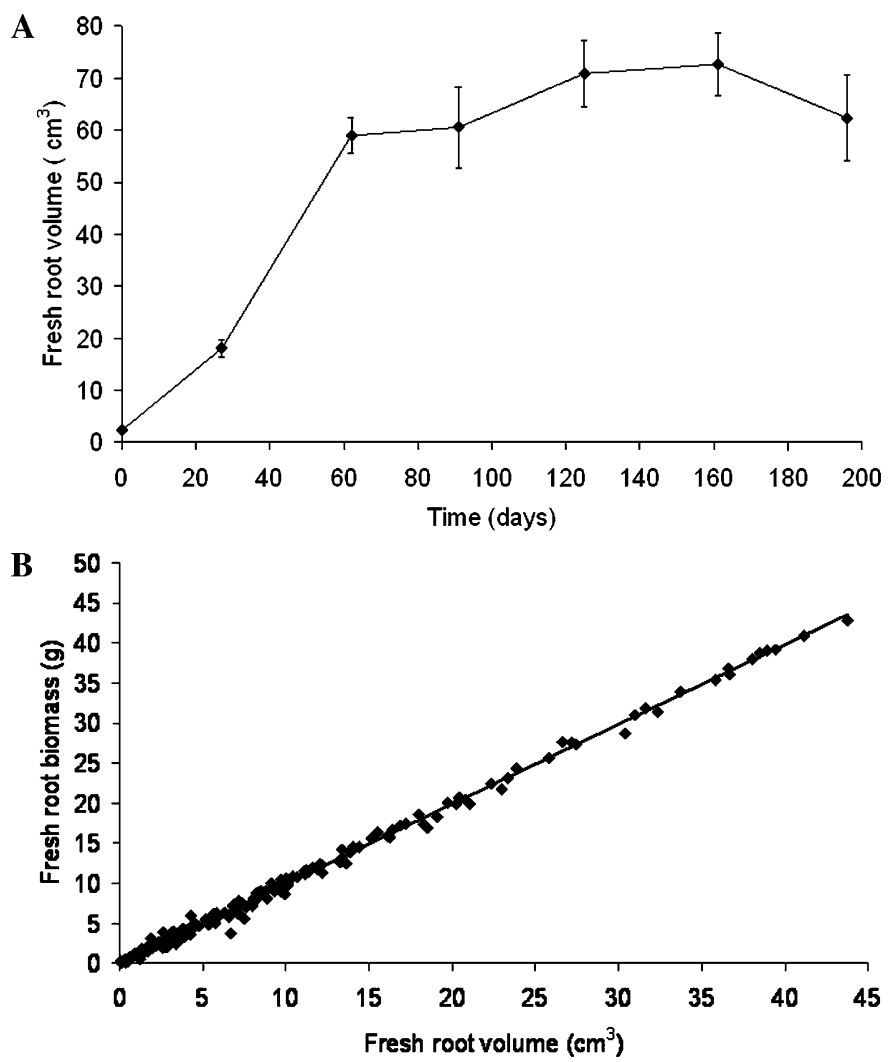

Fig. 3. Root growth during the 196-d experiment. (A) Fresh root volume (in $\mathrm{cm}^{3}$, obtained after washing in water); (B) linear relationship between fresh root biomass $(\mathrm{g})$ and fresh root volume $\left(\mathrm{cm}^{3}\right)(\mathrm{RB}=0.995 \times$ $\left.\mathrm{RV}, R^{2}=0.997, P<0.001\right)$. Bars represent SES $(\mathrm{n}=3)$.

continuous measurement of water content and water pressure every $10 \mathrm{~min}$ during evaporation of the substrate made it possible to calculate the water flux $\mathrm{q}$ through the column (Green et al., 1986):

$$
q=-\frac{\Delta \theta_{h 1}-\Delta \theta_{h 2}}{\Delta t}
$$

where $q$ is expressed in $\mathrm{m} \cdot \mathrm{s}^{-1}, \Delta \theta_{h 1}$ and $\Delta \theta_{h 2}$ are the temporal changes in water storage at depths $h_{1}$ and $h_{2}(\mathrm{~m})$, and $\Delta \mathrm{t}$ is the time variation (s).

The unsaturated hydraulic conductivity $K(\theta)$ (expressed in $\mathrm{m} \cdot \mathrm{s}^{-1}$ ) is then obtained by dividing the fluxes calculated previously with the hydraulic gradient $(d \psi)$ at the same positions $\left(d z=h_{1}-h_{2}\right)$ and times:

$$
K(\theta)=\frac{-q}{\left(\frac{d \psi}{d z}-1\right)}
$$

Table 1. Volumetric proportion of 'New Guinea' impatiens roots and changes in total porosity of a sphagnum peatmoss substrate over $196 \mathrm{~d}$ of growth with subirrigation held constant at $-1 \mathrm{kPa}$.

\begin{tabular}{ccc}
$\begin{array}{l}\text { Time } \\
(\text { days })\end{array}$ & $\begin{array}{c}\text { Proportion of } \\
\text { roots }(100 \times \mathrm{v} / \mathrm{v})\end{array}$ & $\begin{array}{c}\text { Total porosity } \\
(\mathrm{v} / \mathrm{v})\end{array}$ \\
\hline 0 & $0.21(0.04)$ & $0.931(0.000)$ \\
27 & $1.66(0.15)$ & $0.914(0.001)$ \\
62 & $5.39(0.31)$ & $0.877(0.003)$ \\
91 & $5.54(0.71)$ & $0.875(0.007)$ \\
125 & $6.49(0.58)$ & $0.866(0.006)$ \\
161 & $6.65(0.56)$ & $0.864(0.006)$ \\
196 & $5.70(0.76)$ & $0.874(0.008)$ \\
\hline
\end{tabular}

Numbers in parentheses are SES.

\section{Data treatment}

Water retention modeling. Water retention data were modeled using the van Genuchten (1980) model:

$$
\theta=\theta_{r}+\left(\theta_{s}-\theta_{r}\right) \times\left[\left(1+(\alpha . \psi)^{n}\right)\right]^{-m}
$$

where $\psi$ is the soil water suction $(\mathrm{kPa}), \theta$ is the soil volumetric water content $\left(\mathrm{m}^{3} \cdot \mathrm{m}^{-3}\right), \theta_{s}$ is the soil saturation volumetric water content $\left(\mathrm{m}^{3} \cdot \mathrm{m}^{-3}\right)$ corresponding to the total porosity presented above, $\theta_{r}$ is the soil residual volumetric water content $\left(\mathrm{m}^{3} \cdot \mathrm{m}^{-3}\right)$ and $\alpha\left(\mathrm{kPa}^{-1}\right)$, $n$ (dimensionless) and $m=1-1 / n$ (dimensionless) are fitting parameters.
Unsaturated hydraulic conductivity. The van Genuchten (1980) model was used to describe the hydraulic conductivity characteristics:

$$
\begin{aligned}
K(\theta)= & K s\left(\frac{\theta-\theta_{r}}{\theta_{s}-\theta_{r}}\right)^{\tau} \\
& \times\left[1-\left(1-\left(\frac{\theta-\theta_{r}}{\theta_{s}-\theta_{r}}\right)^{\frac{1}{m}}\right)^{m}\right]^{2}
\end{aligned}
$$

where $K s$ is the saturation hydraulic conductivity $\left(\mathrm{m} \cdot \mathrm{s}^{-1}\right)$ and $\tau$ is tortuosity $\left(\mathrm{m} \cdot \mathrm{m}^{-1}\right)$.

$$
K(\psi)=K s\left(\frac{1-(\alpha \psi)^{n-2}\left[1+(\alpha \psi)^{n}\right]^{-m}}{\left[1+(\alpha \psi)^{n}\right]^{2 m}}\right)
$$

\section{Statistical analysis}

Modeling of the van Genuchten curves was analyzed using the calculation of the root mean squared error (RMSE) and analysis of variance. Mean difference testing at the $90 \%$ and $95 \%$ thresholds was used either for respective values of $5 \%$ and $10 \%$ or for the first species error (R software; GNU General Public License, USA). For other results, SES were calculated (between brackets in the tables).

\section{Results}

Peat water content stability. The mean volumetric water content continuously increased during the first $160 \mathrm{~d}$ of the experiment and appeared to stabilize thereafter in the $\mathrm{P}$ treatment (Fig. 2). In the NP treatment, the volumetric water content did not significantly change from Day 60 to Day $196(P<0.1)$. The mean volumetric water content in $\mathrm{P}$ and NP treatments was not different during the first $125 \mathrm{~d}$ of the experiment, after which it was slightly higher in P treatments. At the end of the experiment, the volumetric water content was 1.27 and 1.19 times higher than their initial values in P and NP treatments, respectively.

Plant growth. Fresh root volume could be broken down into three stages during plant growth (Fig. 3A). From Day 27 to Day 60 , root growth was the highest, reaching $59 \mathrm{~cm}^{3}$ fresh 
volume. Root growth then slowed down until Day 161. Finally, fresh root volume seemed to decrease over the last $30 \mathrm{~d}$, although it was not statistically different. The very good correlation between fresh root biomass and fresh root volume $\left(R^{2}=0.997, P<0.001\right.$; Fig. 3B) led to a root density of almost $1 \mathrm{~g} \cdot \mathrm{cm}^{-3}$. Moreover, the linearity of this correlation confirmed the homogeneity of the root density in all parts of the substrate. During the experiment, we did not observe any change in peat volume in NP and $\mathrm{P}$ treatments. The volumetric percentage of root in the cylinder is presented in Table 1. After the first stage of root growth, it reached 5.4\%. The maximum was attempted at Day 161 with $6.7 \%$.

Growing media water retention. Growing media water retention curves showed a significant and regular increase in water retention over the $196 \mathrm{~d}$ of the experiment in the range of water potentials studied (Fig. 4), except for a slight decrease at saturation, corresponding to the total porosity. Fitted Van Genuchten parameters are presented in Table 2. The model accurately represented the experimental data with regard to the RMSE. Using the Van Genuchten model, it was possible to analyze the equivalent pore distribution. This distribution reaches a maximum value at a water potential $\psi_{\max }=\alpha^{-1} \times m^{-1 / n}$ (Dexter and Bird, 2001). On the basis of this value, Jurin's law makes it possible to obtain an equivalent pore radius. The equivalent pore radius was divided by 2.4 at the end of the experiment (Fig. 5). It varied from $1867 \mu \mathrm{m}$ to $766 \mu \mathrm{m}$ at Day 0 and Day 196, respectively.

Growing media hydraulic conductivity. Changes in the unsaturated hydraulic conductivity were observed during the experiment. The saturation hydraulic conductivity $K s$ estimated by the Van Genuchten model was divided by 3.7 and varied from $4.810^{-5}$ and $1.310^{-5} \mathrm{~m} \cdot \mathrm{s}^{-1}$ at Days 0 and 196 , respectively (Table 3). The Van Genuchten model provided a satisfactory representation of the experimental data with regard to $R^{2}$. Although $K s$ were comparable at the beginning and the end of the experiment, the unsaturated hydraulic conductivity curves $K(\theta)$ had different shapes $(P<$ 0.1 ; Fig. 6A-B) and are always lower at Day 196 than at Day $0(P<0.1)$.

\section{Discussion}

Relationships among water retention, hydraulic conductivity, and root growth. During the experiment, we did not observe any change in peat volume in NP and P treatments. The peat bulk density increased very slightly, from 0.107 to $0.112 \mathrm{~g} \cdot \mathrm{cm}^{-3}$, at the beginning and at the end of the experiment, respectively. This increase in bulk density was therefore not the explanation for the volumetric water content increase. The large initial water content increase was mainly the result of solid particle arrangement. Root activity was not yet pronounced at Day 27 but thereafter it played an important role during the rest of the experiment.

Root dry biomass at the end of the experiment was higher than that of Caron et al. (2010) who measured a dry biomass of almost $2.9 \mathrm{~g}$ in pure peat after $84 \mathrm{~d}$ with 'New Guinea'

Table 2. Hydraulic model parameters of Eq. [5] for peat water retention curves $\psi(\theta){ }^{\mathrm{z}}$

\begin{tabular}{lccccc}
\hline Reference & $\theta s\left(\mathrm{~m}^{3} \cdot \mathrm{m}^{-3}\right)$ & $\theta r\left(\mathrm{~m}^{3} \cdot \mathrm{m}^{-3}\right)$ & $\alpha\left(\mathrm{kPa}^{-1}\right)$ & $n$ & $\mathrm{RMSE}\left(\mathrm{m}^{3} \cdot \mathrm{m}^{-3}\right)$ \\
\hline NP 0 & 0.931 & 0.263 & 17.965 & 2.060 & 0.006 \\
NP 196 & 0.931 & 0.250 & 27.497 & 1.585 & 0.009 \\
P 27 & 0.914 & 0.277 & 14.798 & 1.969 & 0.001 \\
P 91 & 0.875 & 0.250 & 15.284 & 1.712 & 0.020 \\
P 161 & 0.864 & 0.250 & 12.795 & 1.575 & 0.007 \\
P 196 & 0.874 & 0.250 & 9.183 & 1.575 & 0.017 \\
\hline
\end{tabular}

${ }^{2}$ The peat saturation volumetric water content $(\theta s)$ corresponded to the calculated total porosity (Eq. [2]), the peat residual water content $(\theta r)$, and parameters $\alpha$ and $n$ are fitted values obtained from the Van Genuchten model. Model performance was appreciated calculating the root mean squared error (RMSE). These curves were established at Days 0 and 196 for peat substrate without impatiens (NP) and at Days 27, 91, 161, and 196 for peat substrate with impatiens (P).

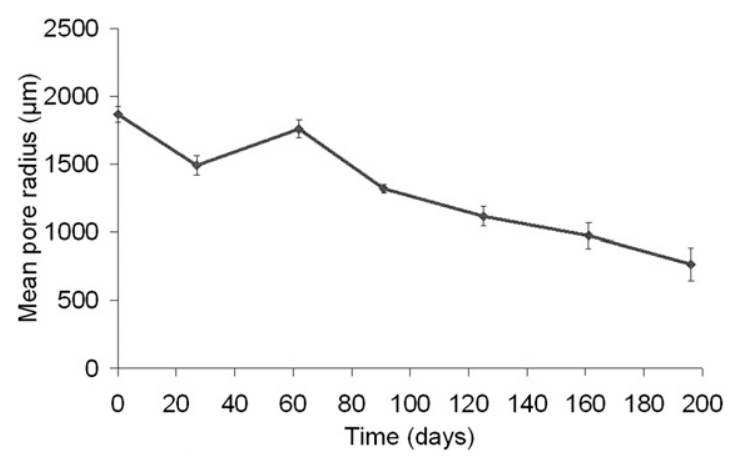

Fig. 5. Changes in the mean pore radius $(\mu \mathrm{m})$ during root growth in the growing media. The mean pore radius was calculated from Van Genuchten model parameters. Bars represent SEs $(n=3)$.

$\mathbf{A}$
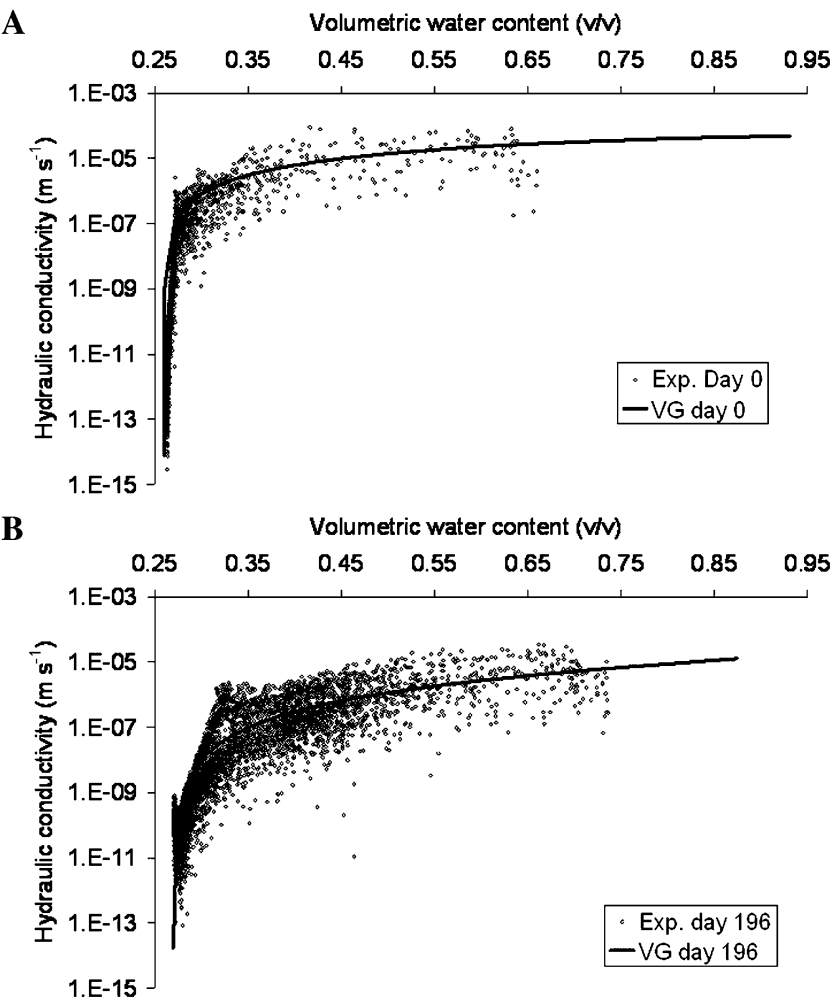

Fig. 6. Relationship between the peat unsaturated hydraulic conductivity and the peat volumetric water content $K(\theta)$. (A) $K(\theta)$ experimental data were obtained from the instantaneous profile method, and they were fitted with the Van Genuchten model (VG) at Day 0; (B) $K(\theta)$ experimental data were obtained from the instantaneous profile method, and they were fitted with the Van Genuchten model (VG) at Day 196.

impatiens grown in the same container volume but not under a constant water regimen. The volumetric percentage of root in the cylinder was relatively low compared with Raviv and
Lieth (2008) who reported a root volume of $\approx 10 \%$ for low-volume containers. This maximal root volume was as high as the peat volume that represented $6.8 \%$ of the container volume. 
Because the total porosity did not vary in the NP treatment, the decrease in total porosity for the $\mathrm{P}$ treatment (7.1\% from Day 0 to Day 161$)$ can be linked to the root development described previously. It was higher than Allaire-Leung et al. (1999) who observed a decrease of $3.8 \%$ in total porosity but for a 5-L container volume with Prunus $\times$ Cistena sp.

Peat water retention curves gave interesting results about the water and air availabilities. Considering the water-holding capacity at a water potential of $-1 \mathrm{kPa}$, it increased from 0.58 to $0.75 \mathrm{~m}^{3} \cdot \mathrm{m}^{-3}$ (i.e., by $29.3 \%$ ) in $196 \mathrm{~d}$. On the basis of these curves, it was calculated that the water availability (calculated by the difference of volumetric water contents at -1 and $-10 \mathrm{kPa}$ ) remained constant with a mean of $0.31 \mathrm{~m}^{3} \cdot \mathrm{m}^{-3}$. In contrast, the air availability (calculated by the difference of volumetric water contents at 0 and $-1 \mathrm{kPa}$ ) progressively decreased over time from 0.35 to $0.14 \mathrm{~m}^{3} \cdot \mathrm{m}^{-3}$.

Table 3A. Hydraulic model parameters of Eq. [6] for the hydraulic conductivity $K(\theta){ }^{\mathrm{z}}$

\begin{tabular}{lllcc}
\hline Sample & \multicolumn{1}{c}{$K s$} & $m$ & $\tau$ & $R^{2}$ \\
\hline NP 0 & $4.8310^{-5}$ & 1.6 & 0.5 & 0.64 \\
P 196 & $1.2810^{-5}$ & 1.09 & 0.1 & 0.58
\end{tabular}

zThe saturation hydraulic conductivity $(K s)$, the tortuosity $(\tau)$ and $m$ are fitted parameters. The correlation coefficient $R^{2}$ is also presented. These curves were established at Day 0 for peat substrate without impatiens (NP) and at Day 196 for peat substrate with impatiens (P).
Thus, in this study, it clearly appeared that roots contributed to the increase in water retention capacity of the growing media by decreasing the macroporosity and increasing the microporosity. In the case of impatiens, this phenomenon was progressive up to $196 \mathrm{~d}$, even if the root growth slowed down after $60 \mathrm{~d}$. From Day 160 to Day 196, we observed a change in root color. Some might have deteriorated as a possible consequence of lower air availability and/or the consequence of the senescent phase of impatiens growth. The increase of waterholding capacity has also been observed by several authors in a mixed peat and coniferous bark wood substrate (Allaire-Leung et al., 1999; Nkongolo and Caron, 2006b). The variation of the saturation hydraulic conductivity $K s$ from Day 0 to Day 196 (from $4.810^{-5}$ and $1.310^{-5}$ $\mathrm{m} \cdot \mathrm{s}^{-1}$ ) was in line with the equivalent pore radius decrease during the experiment. Using the Darcy and Poiseuille laws, the following equation was obtained:

$$
K s=-\frac{\rho \cdot g}{8 . v_{d}} \times \frac{P t \cdot R^{2}}{\tau^{2}}
$$

where $\mathrm{R}$ is the pore radius, $\rho$ is water density, and $v_{\mathrm{d}}$ is the dynamic viscosity of water.

Using Eq. [8], if our equivalent pore radius is divided by approximately two, then $\mathrm{K}_{\mathrm{s}}$ would be divided by four. Saturated hydraulic conductivity values obtained in our experiment were lower than those obtained by Nkongolo and Caron (2006a, 2006b) where
A

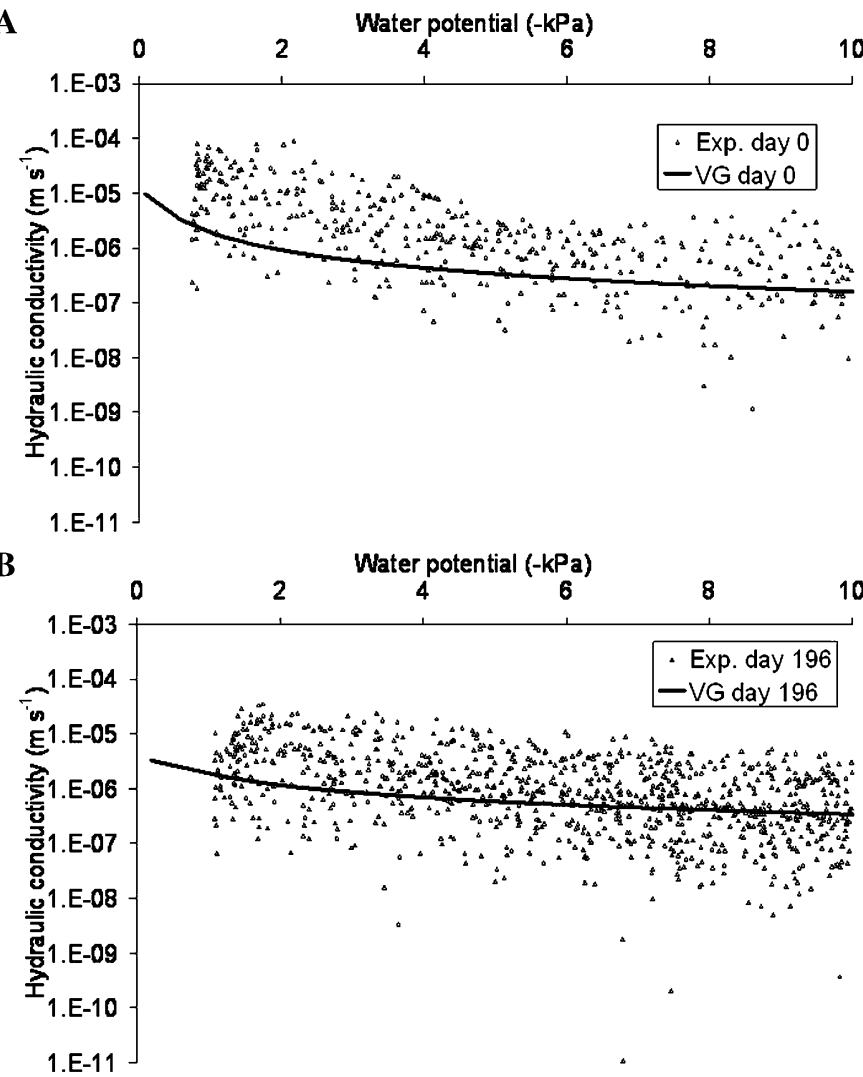

Fig. 7. Relationship between the peat unsaturated hydraulic conductivity and the peat water potential $K(\psi)$. (A) $K(\psi)$ experimental data were obtained from the instantaneous profile method, and they were fitted with the Van Genuchten model (VG) at Day 0; (B) $K(\psi)$ experimental data were obtained from the instantaneous profile method, and they were fitted with the Van Genuchten model (VG) at Day 196.
$K s$ was $\approx 10^{-3} \mathrm{~m} \cdot \mathrm{s}^{-1}$ in a peat-coniferous bark mix. Our values were quite similar to those of Naasz et al. (2005) who measured $K s$ of $810^{-5} \mathrm{~m} \cdot \mathrm{s}^{-1}$ in pure peat with a fine particle size range of 0 to $5 \mathrm{~mm}$.

Consequences of root growth on peat structuration and water irrigation regimen. The decrease in hydraulic conductivity during root growth raised questions about the modification of the total porosity, pore size distribution, and connectivity. Tortuosity is an indicator of pore connectivity. The higher it is, the lower the connectivity. Tortuosity was estimated by fitting $K(\theta)$ curves (Table $3 \mathrm{~A}$ ). It decreased from 0.5 to 0.1 during the experiment. Changes in tortuosity could also be addressed by interpreting the general behavior of $K(\psi)$ curves at Day 0 and Day 196 (Fig. 7A-B; Table 3B). From 0 to $10 \mathrm{kPa}$, no significant differences in $K(\psi)$ were observed between Days 0 and $196(P<0.01)$. This result must be interpreted on the basis of both water retention curves and changes in the mean pore radius. We in fact observed a decrease in air availability and mean pore radius with root growth, whereas $K(\psi)$ did not change. This would imply that pore connectivity was better and that tortuosity decreased. Root growth has a considerable impact on pore organization changes. Several authors have indicated that growing media tortuosity decreased with root growth (Caron et al., 2010; Nkongolo and Caron, 2006a, 2006b).

Finally, in this study, we showed that the main consequence of root growth was the modification of the total porosity of growing media, pore size distribution, and pore connectivity, which resulted in higher water retention and both lower hydraulic conductivity and tortuosity over time. However, these results have to be carefully qualified with regard to other possible processes induced by root growth. We did not take into account exudates from which new organic components were diffused into the growing media. Young (1995) measured higher water contents in the rhizosphere than in the bulk soil. He suggested that mucilage increased the waterholding capacity of the rhizosphere.

This study did not take the spatial distribution heterogeneity of roots into account, which obviously masks the spatial heterogeneity of the hydraulic properties of growing media. Root growth in containers is generally characterized by extensive root colonization at the edge of the container. Future research should focus on the characterization of these heterogeneities to predict spatial water and air availabilities as accurately as possible.

Table 3B. Hydraulic model parameters of Eq. [7] for the hydraulic conductivity $K(\psi){ }^{\mathrm{z}}$

\begin{tabular}{lrlc}
\hline Sample & $\alpha$ & $n$ & $R^{2}$ \\
\hline NP 0 & 17.965 & 1.55 & 0.69 \\
P 196 & 9.183 & 1.4 & 0.55 \\
\hline
\end{tabular}

${ }^{\mathrm{z}} \alpha$ and $n$ are fitted parameters. The correlation coefficient $R^{2}$ is also presented. These curves were established at Day 0 for peat substrate without impatiens (NP) and at Day 196 for peat substrate with impatiens $(\mathrm{P})$. 
As plant canopies grow, they transpire greater volumes of water and thus require greater volumes of irrigation. With increased water need, growing media air porosity is decreasing. Thus, recommendations for water irrigation regimens in the commercial sector would be useful. However, the impact of the decrease in air-filled porosity is not known because it could lead to decreased aeration but may also have no impact if pore connectivity improvement leads to better air exchange. This point deserves further investigation.

\section{Literature Cited}

Allaire-Leung, S.E., J. Caron, and J.L.E. Parent. 1999. Changes in physical properties of peat substrates during plants growth. Can. J. Soil Sci. 79:137-139.

Caron, J., P. Morel, L.M. Rivière, and G. Guillemain. 2010. Identifying appropriate methodology to diagnose aeration limitations with large peat and bark particles in growing media. Can. J. Soil 90:418-494.

Dexter, A.R. and N.R.A. Bird. 2001. Methods for predicting the optimum and the range of water contents for tillage based on the water retention curve. Soil Tillage Res. 57:203-212.

EN 13037. 2000. Amendements du sol et supports de culture-Détermination du $\mathrm{pH}$. Association Française de Normalisation, Paris, France.

EN 13038. 2000. Amendements du sol et supports de culture-Détermination de la conductivité électrique. Association Française de Normalisation, Paris, France.

EN 13039. 2000. Amendements du sol et supports de culture-Détermination de la teneur en matières organiques. Association Française de Normalisation, Paris, France.

EN 13041. 2000. Amendements du sol et supports de culture-Détermination des propriétés physiques-Masse volumique apparente sèche, volume d'air, volume d'eau, valeur de rétrac- tion et porosité totale. Association Française de Normalisation, Paris, France.

Favaro, J.C. and R.P. Marano. 2003. Alterations in the physical and physico-chemical properties of a substrate based on composted sawdust and perlite with polycyclic tomato crops. Span. J. Agr. Res. 1:105-109.

Fonteno, W.C. 1989. An approach to modeling air and water status of horticultural substrates. Acta Hort. 238:67-74.

Fonteno, W.E. 1996. Growing media types and physical/chemical properties, p. 93-122. In Reed, D.W. (ed.). Water, media and nutrition for greenhouse crops, A grower's guide, Ball Publishing, Batavia, IL.

Green, R.E., L.R. Ahuja, and S.K. Chong. 1986. Hydraulic conductivity, diffusivity and sorptivity of unsaturated soils: Fields methods, p. 771-798. In: Klute, A. (ed.). Methods of soil analysis. Part 1. 2nd Ed. Agron. Monogr. 9. ASA and SSSA, Madison, WI.

Gruda, N. and W.H. Schnitzler. 2003. Suitability of wood fiber substrate for production of vegetable transplants. I. Physical properties of wood fiber substrates. Sci. Hort. 100:309-322.

Lemaire, F., A. Dartigues, L.M. Rivière, S. Charpentier, and P. Morel. 2003. Cultures en pots et conteneurs. Principes agronomiques et applications. 2nd Ed. INRA, Paris, France.

Mathers, H.M., S.B. Lowe, C. Scagel, D.K. Struve, and L.T. Case. 2007. Abiotic factors influencing root growth of woody nursery plants in containers. HortTechnology 17:151-162.

Michel, J.C., R. Naasz, and N. Montgermont. 2004 A tool for measuring the shrink/swell phenomena of peat growing media by image analysis. Proc. 12th Intl Peat Cong. 1:321-325.

Michel, J.C., L.M. Rivière, and M.N. BellonFontaine. 2001. Measurement of the wettability of organic materials in relation to water content by the capillary rise method. Eur. J. Soil Sci. 52:459-467.

Morel, P. and C. Berthier. 2005. Utilisation de géotextiles comme nappes d'irrigation: Pro- priétés et caractérisation. PHM Revue horticole 465:18-26.

Naasz, R., J.C. Michel, and S. Charpentier. 2005. Measuring hydraulic properties of peat and pine bark using a transient method. Soil Sci. Soc. Amer. J. 69:13-22.

Naasz, R., J.C. Michel, and S. Charpentier. 2008. Water repellency of organic growing media related to hysteretic water retention properties. Eur. J. Soil Sci. 59:156-165.

Nkongolo, N.V. and J. Caron. 2006a. Pore space organization and plant response in peat substrates: I. Prunus $\times$ cistena and Spirea japonica Scientific Research and Essay 1:77-89.

Nkongolo, N.V. and J. Caron. 2006b. Pore space organization and plant response in peat substrates: II. Dendrathemum morifolium Ramat. Scientific Research and Essay 1:93-102.

Polak, A. and R. Wallach. 2001. Measuring soil moisture dynamics in an irrigated orchard by time reflectrometry method. Acta Hort. 562:39-46.

Qi, G., J.C. Michel, S. Charpentier, and P. Boivin. 2011. A laboratory method for measuring physical properties of growing media and their evolution during drying/wetting cycles: Preliminary results. Acta Hort. 891:181-185.

Raviv, M. and J.H. Lieth. 2008. Soilless culture: Theory and practice. Elsevier, Amsterdam. ISBN 9780444529756.

Riviere, L.M., J.C. Foucard, and F. Lemaire. 1990 Irrigation of container crops according to the substrate. Sci. Hort. 43:339-349.

Schmilewski, G. 2009. Growing medium constituents used in the EU. Acta Hort. 819:33-46.

van Genuchten, M.T. 1980. A closed-form equation for predicting hydraulic conductivity of unsaturated soils. Soil Sci. Soc. Amer. J. 44:892-898.

Verdonck, O., I.M. Cappaert, and F.M. De Boodt. 1978. Physical characterisation of horticultural substrates. Acta Horticulturae. 82:191-200.

Young, I.M. 1995. Variation in moisture contents between bulk soil and the rhizosheath of wheat Triticum-Aestivum 1. cv. wembley. New Phytol. 130:135-139. 